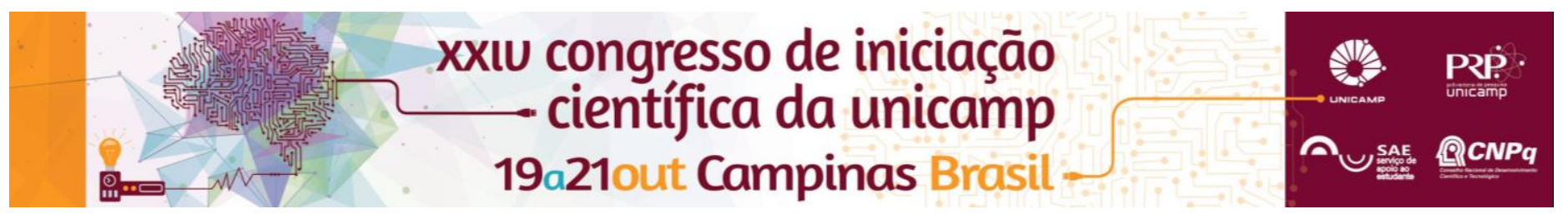

\title{
Repetição da gestação na adolescência: um problema que continua.
}

\author{
Aline D'Annibale*, Daiane S. M. Paulino, Maira Pinho-Pompeu, Rafael B. F. Galvão, Fernanda G. C. Surita
}

\section{Resumo}

Objetivos: Avaliar os fatores de risco de gestações repetidas na adolescência. Métodos: Estudo caso-controle. Dados de adolescentes com repetição da gravidez foram comparados os de adolescentes primíparas e adultas multíparas. Resultados: Adolescentes com repetição da gestação mostraram maior prevalência de união estável, porém menor escolaridade que as pimigestas. A renda familiar mais prevalente entre adolescentes primiparas e multíparas foi inferior ao encontrado nas adultas. Adolescentes realizaram menos revisão puerperal, amamentaram por menor tempo e apresentaram menor intervalo intergestacional. Parto vaginal é mais prevalente entre adolescentes. Conclusão: $O$ seguimento puerperal parece menos efetivo ao público adolescente, ainda que o seu acompanhamento pré-natal aparente se assemelhe ao acompanhamento de adultas. Adolescentes merecem maior atenção não apenas em sua fase pré-natal, mas principalmente no cuidado pós-parto.

\section{Palavras-chave:}

Gestação na adolescência, repetição da gestação, saúde do adolescente.

\section{Introdução}

A gravidez na adolescência é um problema de saúde pública que cursa com maior risco de morbimortalidade materna e perinatal, e são elevadas as taxas de fecundidade nesta faixa etária ${ }^{1}$. Ao engravidarem na adolescência as mulheres tendem a ter um número maior de filhos durante a vida reprodutiva ${ }^{2}$. Fatores de risco biológicos, econômicos e psicológicos são elencados para gestações sucessivas na adolescência ${ }^{3}$.Objetivos: avaliar os fatores de risco de gestações repetidas na adolescência.

\section{Resultados e Discussão}

Foram coletados dados de 14 adolescentes com repetição da gravidez, 30 adolescentes primíparas e 30 adultas com mais de uma gravidez. Foram comparados fatores socioeconômicos e biológicos entre os grupos. $\mathrm{O}$ nº de consultas de pré-natal foi semelhante entre os grupos, com média de 9 consultas; 0 intervalo

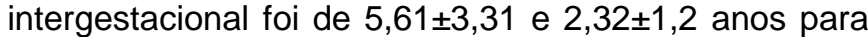
as adultas e para as adolescentes com repetição da gestação respectivamente. $O$ tempo médio de amamentação foi de $12,34 \pm 12,35$ meses nas adultas comparado $9,18 \pm 10,69$ meses nas adolescentes.

Tabela 1. Fatores sociodemográficos associados a repetição da gravidez na adolescência

\begin{tabular}{lccc}
\hline \multicolumn{1}{c}{ Variável } & $\begin{array}{c}\text { Adolescente } \\
\text { multípara } \\
\mathbf{n}(\%)\end{array}$ & $\begin{array}{c}\text { Adolescente } \\
\text { primípara } \\
\mathbf{n}(\%)\end{array}$ & $\begin{array}{c}\text { Adulta } \\
\text { nultípara } \\
\mathbf{n}(\%)\end{array}$ \\
\hline Com companheiro - & $12(85,71)$ & $20(66,67)$ & $26(86,67)$ \\
\hline Escolaridade & $11(78.57)$ & $9(30)$ & $9(30 \%)$ \\
Até 8 anos & $3(21,42)$ & $20(66,66)$ & $16(53,33)$ \\
De 9 a 11 anos & 0 & $1(3,33)$ & $5(16,66)$ \\
Mais de 12 anos & $1(7.14)$ & $2(6,67)$ & 0 \\
\hline Renda familiar (salários mínimos) & $15(50)$ & $11(36,67)$ \\
Sem renda & $8(57.14)$ & $12(40)$ & $16(53,33)$ \\
Entre 1 e 2 & $4(28,57)$ & $1(3,33)$ & $3(10)$ \\
Entre 3 e 5 & $1(7,14)$ & $11(36,67)$ & $6(20)$ \\
Mais que 5 & $3(21.43)$ & $10(33,33)$ & $9(30)$ \\
\hline $\begin{array}{l}\text { Deixou de trabalhar } \\
\text { na 1ª gestação }\end{array}$ & & & \\
\hline $\begin{array}{l}\text { Deixou de estudar } \\
\text { na 1ª gestação }\end{array}$ & $8(57,14)$ & & \\
\hline
\end{tabular}

Tabela 2. Fatores biológicos relacionados a repetição da gravidez na adolescência

\begin{tabular}{lccc}
\hline Variável & $\begin{array}{c}\text { Adolescent } \\
\text { e multípara } \\
\mathbf{n}(\%)\end{array}$ & $\begin{array}{c}\text { Adolescente } \\
\text { primípara } \\
\mathbf{n}(\%)\end{array}$ & $\begin{array}{c}\text { Adulta } \\
\text { multípara } \\
\mathbf{n}(\%)\end{array}$ \\
\hline $\begin{array}{l}\text { Realização } \\
\text { de consulta } \\
\text { puerperal }\end{array}$ & $7(53,85)$ & Não se aplica & $26(86,67)$ \\
\hline $\begin{array}{l}\text { Utilização de MAC } \\
\begin{array}{l}\text { Antes do 10 } \\
\text { filho }\end{array}\end{array}$ & $8(57,14)$ & $23(76,67 \%)$ & $19(63,33)$ \\
$\begin{array}{l}\text { Antes do 2o } \\
\text { filho }\end{array}$ & $12(85,71)$ & Não se aplica & $26(86,67)$ \\
\hline $\begin{array}{l}\text { Parto } \\
\text { vaginal }\end{array}$ & $10(71.43)$ & $23(76.67)$ & $19(63.33)$ \\
\hline (*). Método anticoncepcional (MAC) & & \\
\hline
\end{tabular}

\section{Conclusões}

A gestação tem impacto significativo na vida das adolescentes, que terão sua escolaridade influenciada pelo evento. O seguimento puerperal parece menos efetivo neste público, ainda que 0 seu acompanhamento pré-natal aparente se assemelhe ao acompanhamento de adultas. Adolescentes merecem maior atenção não apenas em sua fase pré-natal, mas principalmente no cuidado pós-parto, em que ainda se pode atuar para minimizar riscos negativos na qualidade de vida e a ocorrência de uma nova gravidez.

\section{Referências}

Este trabalho teve a concessão de bolsa pelo $\mathrm{PIBIC/CNPq}$ e apoio técnico do grupo SAHRAS.

${ }^{1}$ Molina, R.C.; Roca C.G.; Zamorano J.S.; Araya E.G. Family planning and adolescent pregnancy. Best Pract Res Clin Obstet Gynaecol. 2010 Apr; 24(2):209-22. PubMed PMID: 20167542

${ }^{2}$ Rosa, J.A.; Reis, A.O.A.; Tanaka, A.C.A. Gestações Sucessivas na Adolescência. Ver. Bras. Crescimento Des Hum. 2007:17 (1):165-172. ${ }^{3}$ WHO. Health for the world's adolescents: A second chance in the second decade World Health Organization..2014. Disponível em: //apps.who.int/adolescent/second-decade. 